\title{
Work impairment, osteoarthritis, and health-related quality of life among employees in Japan
}

\author{
Ken Nakata ${ }^{1}$, Toshinaga Tsuji ${ }^{2}$, Jeffrey Vietri ${ }^{3}$ and Dena H. Jaffe ${ }^{4^{*}}$ (D)
}

\begin{abstract}
Background: Osteoarthritis $(\mathrm{OA})$ is one of the most common causes of health and work impairment; however, this relationship, especially in Japan, is not well characterized. This study examined work impairment and OA in Japanese workers, specifically the relationship with health-related quality of life (HRQoL) and health status.

Methods: This retrospective, cross-sectional observational study included the data of employed adults with a self-reported OA diagnosis from the 2014 Japan National Health and Wellness Survey. Presenteeism and absenteeism were classified using the Work Productivity and Activity Impairment (WPAl) questionnaire for impairment at work in the past week. Outcome variables included health-related quality of life, which was measured with the revised Medical Outcomes Study 36-Item Short Form Survey Instrument Health Survey (SF-36v2), and depression symptom severity, which was assessed using the Patient Health Questionnaire-9 (PHQ-9).
\end{abstract}

Results: The majority (71.2\%) of respondents with OA reported presenteeism, and $11.1 \%$ reported absenteeism. Presenteeism and absenteeism were both associated with younger age; a lower proportion of respondents with than without presenteeism were married or living with a partner, and a greater proportion of those with absenteeism had comorbid conditions (for all, $p<0.05$ ). Respondents with than without presenteeism reported greater use of medications to relieve OA symptoms (37.3\% versus $20.9 \%, p<0.05$ ), and those with than without absenteeism reported more frequent arthritis-related problems $(p=0.032)$. Among those with presenteeism, depression severity was higher $(5.8 \pm 6.0)$ than for those with no presenteeism $(2.9 \pm 4.3 ; p<0.001)$. Presenteeism was associated with impairments in HRQoL on all metrics for patients with OA, with lower mental (6.4 points) and physical (4.8 points) component scores on the SF-36v2 (for all, $p<0.001$ ).

Conclusions: Seven out of every 10 patients with OA experienced presenteeism, whereas one out of 10 reported absenteeism. OA respondents with presenteeism also showed greater medication use, lower HRQoL across both mental and physical components, and higher depression severity. Workplace interventions and effective treatment options are necessary strategies for improving the health of workers with OA in Japan.

Keywords: Osteoarthritis, Presenteeism, Absenteeism, Health-related quality of life, Depression, Work impairment

\footnotetext{
* Correspondence: dena.jaffe@kantarhealth.com

${ }^{4}$ Health Outcomes Practice, Kantar Health, Ariel Sharon Street 4, 5230048 Tel

Aviv, Israel

Full list of author information is available at the end of the article
}

(c) The Author(s). 2018 Open Access This article is distributed under the terms of the Creative Commons Attribution 4.0 International License (http://creativecommons.org/licenses/by/4.0/), which permits unrestricted use, distribution, and reproduction in any medium, provided you give appropriate credit to the original author(s) and the source, provide a link to the Creative Commons license, and indicate if changes were made. The Creative Commons Public Domain Dedication waiver (http://creativecommons.org/publicdomain/zero/1.0/) applies to the data made available in this article, unless otherwise stated. 


\section{Background}

Osteoarthritis (OA) is a degenerative joint disorder that causes joint pain, stiffness, and restricted movement, and influences health-related quality of life (HRQoL) [1, 2]. According to a recent large-sample review of studies of patients with OA, impairment in HRQoL remains a significant component of the disease burden [3]. Moreover, OA comprises most of the economic loss that is due to arthritis, and by 2020, it is expected to be the world's fourth main cause of disability [4]. It is anticipated that OA will have an even greater effect on health care systems and delivery of health care in the years beyond [2]. In Japan specifically, the prevalence of OA ranges from 10. $0 \%$ to $62.4 \%$ in middle-aged and older individuals, however, OA is present in younger groups, as well [5-7].

Although $\mathrm{OA}$ is viewed as an age-related condition, there is a growing awareness that OA also affects younger individuals who are still employed [8]. Due to the impact of OA on employed individuals, the consideration of indirect costs stemming from productivity losses is an important aspect of assessing OA's economic effects [9]. Indirect costs typically result from absenteeism and presenteeism [10]. Absenteeism represents time off from work caused by health-related non-attendance, disability, and/or workers' compensation. Presenteeism assesses health-related productivity losses that occur while employees are at work [11].

A study examining the effect of OA on work productivity in five European countries reported about $33 \%$ of participants endorsing joint OA were employed [12]. Overall, arthritis-related pain is one of the most frequent pain-related conditions leading to impaired productivity among employed individuals [13]. Arthritis-related pain has been identified as a reason for leaving employment [14]. Furthermore, the pain and inhibited functioning caused by $\mathrm{OA}$ can result in lower worker productivity and early retirement [9], which can subsequently create significant economic losses for employers.

Studies in the US and Europe have reported that OA has a significant impact on worker absenteeism and presenteeism. Workers who were diagnosed with OA and experienced arthritis pain in the last month reported significantly more work impairment than those without OA pain, which was mainly due to presenteeism $[8,15$, 16]. Similarly, prior research in five European countries reported that employees with OA experienced reduced work productivity caused by absenteeism (reported by $7 \%$ ) and presenteeism (reported by 24\%) [12].

The patterns of results reported in the international literature are generally aligned with the limited data from Japan. Notably, in a large international survey of adults with musculoskeletal symptoms (CUPID study), $5 \%$ of the 2280 Japanese workers sampled had reported sickness absences for pain complaints during the past year [17]. Presenteeism among Japanese workers with orthopaedic pain (low back, knee, or limb pain) was found to be most pronounced for physical job demands, ranging from $22.4 \%$ to $26.5 \%$ in the prior 2 weeks [18].

However, there is evidence that absenteeism may not be a useful an indicator of work productivity loss in Japan, relative to Western nations. For instance, among patients with low back pain, which is one of the most common musculoskeletal pains, the prevalence of absenteeism was three times lower in Japan than in the United Kingdom [17]. These authors suggested that in Japan, presenteeism may have more utility than absenteeism as an indicator of work productivity loss.

Beyond the economic burden attributed to OA, prior research has also consistently shown that OA is linked to poor HRQoL $[8,15]$. In a retrospective observational study, US patients with self-reported OA pain reported worse HRQoL, as demonstrated by significantly lower scores on the Physical Component Summary (PCS; 40.1 vs. 50.8), Mental Component Summary (MCS; 46.3 vs. 47.4), and Short Form-6 Dimension (SF-6D; 0.66 vs. 0. 75), compared with controls [8]. Similarly, US adults with moderate or severe self-reported OA had PCS and SF-6D scores that were significantly lower than those of controls, signifying worse HRQoL [15].

Among Japanese adults, musculoskeletal pain has likewise been associated with decrements in HRQoL [19, 20]. For example, patients diagnosed with knee OA via Kellgren-Lawrence grades $\geq 3$ and experiencing knee pain reported lower scores on the PCS and the EuroQoL, with higher scores on the Western Ontario and McMaster Universities Osteoarthritis Index, than patients with Kellgren-Lawrence grades $\leq 1$ [20]. Additionally, among Japanese adults with a self-reported diagnosis of chronic lower back pain, those with severe pain had lower MCS, PCS, and SF-6D scores than counterparts with mild or moderate pain [19].

Several studies have examined the association between OA and HRQoL in Japan, and it has been wellestablished that OA is associated with a substantial health and economic burden. However, the relationship between work productivity loss (i.e., absenteeism and presenteeism) and HRQoL in this patient population is not well understood. Furthermore, despite the association between OA symptoms and lower work productivity, particularly presenteeism, a limited number of studies have reported on individual-level or work factors associated with presenteeism among those who have conditions like OA [21], especially in Japan. Instead, the presenteeism literature on Japanese populations has focused on other conditions or health-related factors, such as lower back pain [22, 23], depression [24, 25], outpatient chemotherapy treatment [26], and dry eyes [27]. This study aimed to address this gap by comparing those 
with OA in Japan who did versus did not report presenteeism across individual characteristics. Overall, the current study focused on the association between work productivity and HRQoL in employed Japanese patients with OA, which is one of the most prevalent musculoskeletal pains. Informed by the prior literature, we hypothesized that, among patients with OA, those with higher work productivity loss are likely to have poorer HRQoL, and the association between work productivity loss and HRQoL is stronger for presenteeism than for absenteeism.

\section{Methods}

\section{Data source and sample}

Data were obtained from the 2014 Japan National Health and Wellness Survey (NHWS, Kantar Health, New York, NY, USA), a large web-based cross-sectional online survey of individuals age 18 and older. Potential respondents to the NHWS are recruited through an existing web-based consumer panel. The consumer panel recruits its members through opt-in emails, co-registration with panel partners, e-newsletter campaigns, banner placements, and both internal and external affiliate networks. Participation is voluntary, and the NHWS uses stratified random sampling with quotas based on gender and age group to ensure the sample reflects the Japanese population, as reported in the US Census International Database. The NHWS includes epidemiological data, as well as data on socio-demographics, current and past medical history, treatment information, health risk behaviors, and health-related outcomes. The Japan NHWS in 2014 was reviewed and found exempt by Pearl IRB.

All responses to NHWS measures were self-reported. Of the total sample $(N=30,000), 565$ respondents reported an OA diagnosis, and the final study sample included 233 respondents who reported receiving an OA diagnosis from a healthcare provider and were currently employed. No exclusion criteria were applied.

\section{Measures \\ Work productivity and activity impairment}

Work productivity impairment was assessed using the Work Productivity and Activity Impairment (WPAI) questionnaire, a six-item validated instrument that consists of four metrics: presenteeism (the percentage of impairment experienced while at work in the past $7 \mathrm{~d}$ because of one's health), absenteeism (the percentage of work time missed because of one's health in the past $7 \mathrm{~d}$ ), overall work productivity loss (an overall impairment estimate that is a combination of absenteeism and presenteeism), and activity impairment (the percentage of impairment in daily activities because of one's health in the past 7 d) [28]. In addition to the continuous measure, presenteeism and absenteeism were categorized according to any versus no impairment for each variable.

\section{HRQoL and health status}

HRQoL was measured using the revised Medical Outcomes Study 36-Item Short Form Survey Instrument (SF-36v2) [29]. This is a multipurpose, generic HRQoL instrument comprised of 36 questions with summary scores. The present analysis included the standard, USbased summary scores for the MCS and PCS, which each have a mean of 50 and standard deviation of 10 in the US population. Scores can be interpreted relative to this population average of 50 , as well as with other comparison groups of interest. Higher scores indicate better HRQoL. In addition, the instrument was also used to generate health state utilities, namely the SF-6D. This preference-based single index measure of health uses general population values; the current study used values based on the general population of the United Kingdom [30]. The SF-6D index has interval scoring properties and yields summary scores on a theoretical 0-1 scale (with an empirical floor of 0.3). Higher scores indicate better HRQoL. Finally, the SF-36v2 instrument is designed to report on eight health concepts (physical functioning, role physical, bodily pain, general health, vitality, social functioning, emotional role limitations, and mental health). The eight-factor health profile presented in the current study is based on the Japanese scoring norms, with a mean of 50 and standard deviation of 10 in the Japanese population; higher scores indicate better functional health [31].

Depression symptoms and severity of depression over the last 2 weeks were assessed using the Patient Health Questionnaire-9 (PHQ-9), a validated scale used to screen for depression and assess its severity [32]. This scale measures depression symptom severity through the frequency in the past 2 weeks of anhedonia, depressed mood, sleep disturbance, lack of energy, appetite disturbance, negative self-feelings, difficulty concentrating, psychomotor retardation or agitation, and thoughts of self-harm. Scores on the PHQ-9 can range from 0 to 27; higher scores indicate more severe depression symptoms.

\section{Respondent characteristics}

Age (in years), gender, marital status (married or living with partner vs. single, divorced, separated or widowed), annual household income $(<¥ 3$ million, ¥3million to $<$ $¥ 5$ million, $¥ 5$ million to $<¥ 8$ million, ¥8million or more, or decline to answer), and level of education categorized at approximately the median (junior/high school, twoyear college, four-year college, or graduate school)) were assessed for all respondents.

Body mass index (BMI) was calculated in kilograms per meter squared from reported height and weight and 
reported as underweight $\left(<18.5 \mathrm{~kg} / \mathrm{m}^{2}\right)$, normal weight $\left(18.5\right.$ to $\left.<25.0 \mathrm{~kg} / \mathrm{m}^{2}\right)$, overweight $\left(25.0\right.$ to $\left.<30.0 \mathrm{~kg} / \mathrm{m}^{2}\right)$ , obese $\left(30.0 \mathrm{~kg} / \mathrm{m}^{2}\right.$ and above), or decline to answer. Information for cigarette smoking was collected using the following two questions "Have you ever smoked cigarettes?" and "Do you currently smoke cigarettes?" These answers were then recoded into a smoking variable reflecting current, former, or never smokers. Alcohol use was based on the question "How often do you drink alcohol?" Responses options ranged from daily to once a month or less often; there was also an option of "I do not drink alcohol." The alcohol use variable was recoded into none vs. any. Vigorous exercise at least $1 \mathrm{~d}$ in the past month was based on the question "How many days in the past month did you exercise vigorously for at least 20 minutes for the purpose of improving or maintaining your health, with the purpose of losing weight, or for enjoyment?" This was then recoded into a yes or no variable.

The Charlson Comorbidity Index (CCI) [33] weights the presence of the following conditions and sums the result: HIV/AIDS, metastatic tumor, lymphoma, leukemia, any tumor, moderate/severe renal disease, hemiplegia, diabetes, mild liver disease, ulcer disease, connective tissue disease, chronic pulmonary disease, dementia, cerebrovascular disease, peripheral vascular disease, myocardial infarction, congestive heart failure, and diabetes with end organ damage. The greater the total index score, the greater the comorbid burden on the patient.

OA-related characteristics included self-reported length of diagnosis in years, type (multiple sites could be provided) and number of joints affected, severity of arthritis (mild, moderate, or severe), frequency of problems with arthritis (daily, 4-6 times a week, 2-3 times a week, once a week, 2-3 times a month, or once a month or less often), and use of prescription medication for arthritis.

\section{Analysis}

All analyses were conducted using IBM Statistical Package for the Social Sciences (SPSS) version 22. Respondent sociodemographic and OA characteristics were described for the sample cohort using means and standard deviations for continuous and count variables, and frequencies and percentages for categorical variables. Respondents with and without presenteeism and those with and without absenteeism were compared on sociodemographic and health-related characteristics using ttests for continuous variables and chi-square tests or Fisher exact tests (for cells with $n<5$ ) for categorical variables. Cohen's $d$ was calculated to examine the magnitude of difference between groups; it is calculated as the difference in means divided by the standard deviations of each group [34]. A difference of 0.2 is considered small, with more expected overlapping values (92\%) between comparison groups, while 0.8 is large, with less overlapping values $(69 \%)$ between groups.

Regression analyses, which incorporated variables in the bivariate comparisons that were at least marginally significant at $p<0.10$, were used to examine adjusted least-square means for HRQoL by level of presenteeism. Due to the relatively small comparison sample for those with and without absenteeism, further examination of health outcomes was restricted to those with and without presenteeism. The ordinary least square linear regression models analyzed health outcomes as a function of presenteeism (reference $=$ no presenteeism vs . any presenteeism). These models were used to demonstrate the burden of presenteeism on patients with physician-diagnosed OA, controlling for confoundersfound to differ between groups at $p<0.1$ in the bivariate analysis. This model was used, since HRQoL was normally distributed. Model fit was assessed according to a significant F-test. All analyses assumed a null hypothesis with a two-sided $\alpha<0.05$.

Correlations were calculated between presenteeism and other outcomes. Spearman's rho was used because of the non-normal distribution of presenteeism.

\section{Results}

A total of 233 employed, adult respondents with OA were examined, with 166 of 233 (71.2\%) reporting presenteeism and 25 of 225 (11.1\%) reporting absenteeism in the past week (Tables 1 and 2). Presenteeism and absenteeism were associated with younger age (presenteeism: any $=52.9 \pm$ 12.4 years vs. none $=57.3 \pm 11.2$ years, $p=0.012$; absenteeism: any $=46.1 \pm 15.3$ years vs. none $=55.4 \pm 11.3$ years, $p$ $<0.001$ ). The only other socio-demographic or healthrelated characteristics that differed between presenteeism groups were marital status and education. Specifically, a lower proportion of individuals with presenteeism was married or living with a partner (any $=62.7 \%$ vs. none $=76.1 \%, p=0.049$ ), and they had greater educational attainment $(p=0.017)$. Those with absenteeism reported a higher comorbidity burden (CCI scores) than OA patient with no absenteeism (any $=3.1 \pm 8.0$ vs. none $=0.7 \pm 3.3 ; p=0.006$ ).

Most OA-related characteristics were similar between those with and without presenteeism or absenteeism (Tables 1 and 2). The use of prescription medication was substantially higher for those with presenteeism (37.3\%) than those without $(20.9 \%, p=0.015)$, and OA-related problems were more frequent for those with absenteeism $(p=0.032)$. No statistically significant differences in sites affected by OA were observed for respondents with or without presenteeism or absenteeism.

Presenteeism was associated with impairments in HRQoL for all metrics at $p<0.001$ for patients with OA (Table 3). Additionally, OA patients with presenteeism 
Table 1 Sociodemographic and osteoarthritis characteristics by presenteeism among respondents with osteoarthritis in Japan, 2014

\begin{tabular}{|c|c|c|c|c|c|c|c|}
\hline \multirow[b]{3}{*}{ Female $(\%, N)$} & \multirow{2}{*}{\multicolumn{2}{|c|}{ Total $(N=233)$}} & \multicolumn{4}{|c|}{ Presenteeism } & \multirow{3}{*}{$\frac{p \text {-value }}{0.206}$} \\
\hline & & & \multicolumn{2}{|c|}{ Presenteeism $(N=166)$} & \multicolumn{2}{|c|}{ No Presenteeism $(N=67)$} & \\
\hline & $43.8 \%$ & 102 & $46.4 \%$ & 77 & $37.3 \%$ & 25 & \\
\hline Age (Mean, SD) & 54.2 & 12.2 & 52.9 & 12.4 & 57.3 & 11.2 & 0.012 \\
\hline Married or living with partner $(\%, N)$ & $66.5 \%$ & 155 & $62.7 \%$ & 104 & $76.1 \%$ & 51 & 0.049 \\
\hline Annual household income $(\%, N)$ & & & & & & & 0.987 \\
\hline$<¥ 3$ million & $14.2 \%$ & 33 & $13.9 \%$ & 23 & $14.9 \%$ & 10 & \\
\hline$¥ 3$ million to $<¥ 5$ million & $20.6 \%$ & 48 & $20.5 \%$ & 34 & $20.9 \%$ & 14 & \\
\hline$¥ 5$ million to $<¥ 9$ million & $36.5 \%$ & 85 & $37.3 \%$ & 62 & $34.3 \%$ & 23 & \\
\hline$¥ 9$ million or more & $21.0 \%$ & 49 & $21.1 \%$ & 35 & $20.9 \%$ & 14 & \\
\hline Decline to answer & $7.7 \%$ & 18 & $7.2 \%$ & 12 & $9.0 \%$ & 6 & \\
\hline Education (\%, N) & & & & & & & 0.017 \\
\hline Junior/High School & $30.5 \%$ & 71 & $26.5 \%$ & 44 & $40.3 \%$ & 27 & \\
\hline 2-year college & $14.6 \%$ & 34 & $16.3 \%$ & 27 & $10.4 \%$ & 7 & \\
\hline 4-year college & $49.4 \%$ & 115 & $53.6 \%$ & 89 & $38.8 \%$ & 26 & \\
\hline Graduate school & $5.6 \%$ & 13 & $3.6 \%$ & 6 & $10.4 \%$ & 7 & \\
\hline CCI (Mean, SD) & 1.1 & 4.8 & 1.0 & 4.4 & 1.5 & 5.6 & 0.462 \\
\hline BMI categories $(\%, N)$ & & & & & & & 0.665 \\
\hline Underweight $(<18.5)$ & $7.7 \%$ & 18 & $7.2 \%$ & 12 & $9.0 \%$ & 6 & \\
\hline Normal (18.5-24.9) & $61.4 \%$ & 143 & $59.0 \%$ & 98 & $67.2 \%$ & 45 & \\
\hline Overweight (25.0-29.9) & $22.7 \%$ & 53 & $24.7 \%$ & 41 & $17.9 \%$ & 12 & \\
\hline Obese (30.0+) & $6.9 \%$ & 16 & $7.2 \%$ & 12 & $6.0 \%$ & 4 & \\
\hline Decline to answer & $1.3 \%$ & 3 & $1.8 \%$ & 3 & $0.0 \%$ & 0 & \\
\hline Smoking status $(\%, N)$ & & & & & & & 0.518 \\
\hline Current smoker & $26.2 \%$ & 61 & $24.1 \%$ & 40 & $31.3 \%$ & 21 & \\
\hline Former smoker & $34.3 \%$ & 80 & $35.5 \%$ & 59 & $31.3 \%$ & 21 & \\
\hline Never smoker & $39.5 \%$ & 92 & $40.4 \%$ & 67 & $37.3 \%$ & 25 & \\
\hline Drinks alcohol $(\%, N)$ & $75.5 \%$ & 176 & $74.1 \%$ & 123 & $79.1 \%$ & 53 & 0.421 \\
\hline Exercise $(\%, N)$ & $51.1 \%$ & 119 & $51.8 \%$ & 86 & $49.3 \%$ & 33 & 0.724 \\
\hline Length of arthritis diagnosis, years ${ }^{\mathrm{a}}$ (Mean, SD) & 8.4 & 11.3 & 8.4 & 11.0 & 8.2 & 12.0 & 0.897 \\
\hline Number of joints affected (Mean, SD) & 2.0 & 1.9 & 1.9 & 1.7 & 2.1 & 2.2 & 0.482 \\
\hline \multicolumn{8}{|l|}{ Site affected by arthritis $(\%, N)$} \\
\hline Ankles & $15.9 \%$ & 37 & $17.5 \%$ & 29 & $11.9 \%$ & 8 & 0.330 \\
\hline Elbows & $13.3 \%$ & 31 & $12.0 \%$ & 20 & $16.4 \%$ & 11 & 0.397 \\
\hline Feet & $14.6 \%$ & 34 & $14.5 \%$ & 24 & $14.9 \%$ & 10 & 1.000 \\
\hline Fingers/Hands & $26.6 \%$ & 62 & $25.3 \%$ & 42 & $29.9 \%$ & 20 & 0.477 \\
\hline Hips & $14.2 \%$ & 33 & $15.1 \%$ & 25 & $11.9 \%$ & 8 & 0.679 \\
\hline Knees & $51.9 \%$ & 121 & $50.6 \%$ & 84 & $55.2 \%$ & 37 & 0.564 \\
\hline Neck & $10.3 \%$ & 24 & $10.2 \%$ & 17 & $10.4 \%$ & 7 & 1.000 \\
\hline Shoulders & $14.2 \%$ & 33 & $12.0 \%$ & 20 & $19.4 \%$ & 13 & 0.151 \\
\hline Spine & $3.0 \%$ & 7 & $3.0 \%$ & 5 & $3.0 \%$ & 2 & 1.000 \\
\hline Wrists & $16.7 \%$ & 39 & $17.5 \%$ & 29 & $14.9 \%$ & 10 & 0.702 \\
\hline Other & $6.0 \%$ & 14 & $4.2 \%$ & 7 & $10.4 \%$ & 7 & 0.123 \\
\hline \multicolumn{8}{|l|}{ Severity of arthritis $(\%, N)$} \\
\hline Mild & $51.5 \%$ & 120 & $51.2 \%$ & 85 & $52.2 \%$ & 35 & 0.959 \\
\hline
\end{tabular}


Table 1 Sociodemographic and osteoarthritis characteristics by presenteeism among respondents with osteoarthritis in Japan, 2014 (Continued)

\begin{tabular}{|c|c|c|c|c|c|c|c|}
\hline \multirow[b]{3}{*}{ Moderate } & & & \multicolumn{4}{|c|}{ Presenteeism } & \multirow{3}{*}{$p$-value } \\
\hline & \multicolumn{2}{|c|}{ Total $(N=233)$} & \multicolumn{2}{|c|}{ Presenteeism $(N=166)$} & \multicolumn{2}{|c|}{ No Presenteeism $(N=67)$} & \\
\hline & $38.6 \%$ & 90 & $39.2 \%$ & 65 & $37.3 \%$ & 25 & \\
\hline Severe & $9.9 \%$ & 23 & $9.6 \%$ & 16 & $10.4 \%$ & 7 & \\
\hline Frequency of problems with arthritis $(\%, \mathrm{~N})$ & & & & & & & 0.520 \\
\hline Daily & $33.0 \%$ & 77 & $35.5 \%$ & 59 & $26.9 \%$ & 18 & \\
\hline 4-6 times a week & $7.7 \%$ & 18 & $8.4 \%$ & 14 & $6.0 \%$ & 4 & \\
\hline 2-3 times a week & $12.9 \%$ & 30 & $13.3 \%$ & 22 & $11.9 \%$ & 8 & \\
\hline Once a week & $2.6 \%$ & 6 & $3.0 \%$ & 5 & $1.5 \%$ & 1 & \\
\hline $2-3$ times a month & $14.2 \%$ & 33 & $12.0 \%$ & 20 & $19.4 \%$ & 13 & \\
\hline Once a month or less often & $29.6 \%$ & 69 & $27.7 \%$ & 46 & $34.3 \%$ & 23 & \\
\hline Use a prescription for OA $(\%, N)$ & $32.6 \%$ & 76 & $37.3 \%$ & 62 & $20.9 \%$ & 14 & 0.015 \\
\hline
\end{tabular}

Note: $B M I$ body mass index, $C C l$ Charlson Comorbidity Index, $O A$ osteoarthritis

*Differences between none vs. any presenteeism were performed using t-tests for continuous variables and chi-square or Fisher exact (cells < 5) tests for categorical variables

a Data for length of diagnosis were missing for an additional 12 respondents overall

reported lower MCS (6.4 points) and PCS (4.8 points) scores than those with no presenteeism. In the overall SF-6D health utility index, patients with presenteeism had a 0.07-point lower score than those without presenteeism. Health status, according to the eight health domains, was substantially lower by $6.1-9.0$ points for those with than without presenteeism. Those with presenteeism $(5.8 \pm 6.0)$ had greater depression symptom severity, as measured using the PHQ-9 than those without presenteeism $(2.9 \pm 4.3, p<0.001)$.

Similar differences in HRQoL were observed in regression analyses after adjusting for covariates age, marital status, and education (Fig. 1). Adjusted means were lower for both the MCS and PCS, as well as for all eight measures of health status $(p \leq 0.001)$. Adjusted means for the SF-6D health utility score remained lower for those with (vs. without) presenteeism $(0.67 \pm 0.01$ vs. $0.74 \pm 0.02, p<0.001)$.

Work and activity impairment, which were examined in relation to presenteeism, were substantially higher among employed OA respondents with, compared to without, presenteeism (Table 4). More patients with than without presenteeism reported absenteeism (15.1\% vs. 1 . $5 \%, p=0.001)$. Specifically, absenteeism and overall work impairment were greater among those with than without presenteeism (absenteeism: $2.9 \% \pm 10.8 \%$ vs. $0.0 \% \pm 0.4 \%$, $p=0.034$; overall work impairment: $39.5 \% \pm 25.1 \%$ vs. 0 . $0 \% \pm 0.4 \%, p<0.001)$. Activity impairment was significantly higher among those with presenteeism than without $(38.7 \% \pm 25.3 \%$ vs. $6.7 \% \pm 18.5 \%, p<0.001)$.

When considered as continuous variables, presenteeism was negatively associated with all of the HRQoL indicators and positively associated with depression characteristics (for all, $p<0.001$ ) (Table 5). Higher presenteeism was moderately associated with lower MCS, PCS, and SF6D scores, with the strongest correlation being with health utility scores (rho $=-0.51, p<0.001$ ). Higher presenteeism was associated with lower functional health status on all eight SF-36v2 health profile scores using the Japanese norm-based scoring. These correlations ranged from rho $=-0.37$ for emotional role limitations to rho $=-0.49$ for physical role limitations, with other measures falling between these two extremes. Higher presenteeism was also moderately related to greater depression severity, based on PHQ-9 scores $($ rho $=0.42, p<0.001)$.

\section{Discussion}

In the current study, $71.2 \%$ respondents with OA reported some degree of impairment at work, while only $11.1 \%$ reported missing work due to a health-related problem. The results show that, among employed adults, those with OA and presenteeism tend to be younger, not married or living with a partner, and report a greater use of OA medication. Respondents with presenteeism had substantially lower HRQoL than those without presenteeism.

This and other studies show that, while OA affects health outcomes, the larger impact to work impairment is from presenteeism and not absenteeism [8, 12, 15]. A study of Japanese workers with musculoskeletal pain hypothesized that presenteeism among workers in Japan may be more prevalent, compared with workers in other countries, due to cultural differences surrounding concerns about absence from work [16]. Thus, although respondents with absenteeism appear to have a greater health burden (i.e., higher $\mathrm{CCI}$ scores and more OArelated problems), few patients with $\mathrm{OA}$ report absenteeism. In contrast, presenteeism represents a larger 
Table 2 Sociodemographic and osteoarthritis characteristics by absenteeism among respondents with osteoarthritis in Japan, 2014

\begin{tabular}{|c|c|c|c|c|c|c|c|}
\hline \multirow[b]{3}{*}{ Female $(\%, N)$} & & & \multicolumn{4}{|c|}{ Absenteeism $^{a}$} & \multirow{3}{*}{$\frac{p \text {-value }}{0.420}$} \\
\hline & \multicolumn{2}{|c|}{ Total $(N=233)$} & \multicolumn{2}{|c|}{ Absenteeism $(N=25)$} & \multicolumn{2}{|c|}{ No Absenteeism $(N=200)$} & \\
\hline & $43.8 \%$ & 102 & $52.0 \%$ & 13 & $43.5 \%$ & 87 & \\
\hline Age (Mean, SD) & 54.2 & 12.2 & 46.1 & 15.3 & 55.4 & 11.3 & $<0.001$ \\
\hline Married or living with partner $(\%, N)$ & $66.5 \%$ & 155 & $64.0 \%$ & 16 & $68.0 \%$ & 136 & 0.687 \\
\hline Annual household income $(\%, N)$ & & & & & & & 0.204 \\
\hline$<¥ 3$ million & $14.2 \%$ & 33 & $8.0 \%$ & 2 & $15.0 \%$ & 30 & \\
\hline$¥ 3$ million to $<¥ 5$ million & $20.6 \%$ & 48 & $16.0 \%$ & 4 & $21.0 \%$ & 42 & \\
\hline$¥ 5$ million to $<¥ 9$ million & $36.5 \%$ & 85 & $32.0 \%$ & 8 & $37.5 \%$ & 75 & \\
\hline$¥ 9$ million or more & $21.0 \%$ & 49 & $40.0 \%$ & 10 & $18.0 \%$ & 36 & \\
\hline Decline to answer & $7.7 \%$ & 18 & $4.0 \%$ & 1 & $8.5 \%$ & 17 & \\
\hline Education $(\%, N)$ & & & & & & & 0.584 \\
\hline Junior/High School & $31.1 \%$ & 70 & $24.0 \%$ & 6 & $32.0 \%$ & 64 & \\
\hline 2-year college & $14.2 \%$ & 32 & $20.0 \%$ & 5 & $13.5 \%$ & 27 & \\
\hline 4-year college & $50.2 \%$ & 113 & $48.0 \%$ & 12 & $50.5 \%$ & 101 & \\
\hline Graduate school & $4.4 \%$ & 10 & $8.0 \%$ & 2 & $4.0 \%$ & 8 & \\
\hline CCI (Mean, SD) & 1.1 & 4.8 & 3.1 & 8.0 & 0.7 & 3.3 & 0.006 \\
\hline BMI categories $(\%, N)$ & & & & & & & 0.557 \\
\hline Underweight $(<18.5)$ & $7.7 \%$ & 18 & $8.0 \%$ & 2 & $8.0 \%$ & 16 & \\
\hline Normal (18.5-24.9) & $61.4 \%$ & 143 & $68.0 \%$ & 17 & $60.5 \%$ & 121 & \\
\hline Overweight (25.0-29.9) & $22.7 \%$ & 53 & $12.0 \%$ & 3 & $23.5 \%$ & 47 & \\
\hline Obese (30.0+) & $6.9 \%$ & 16 & $12.0 \%$ & 3 & $6.5 \%$ & 13 & \\
\hline Decline to answer & $1.3 \%$ & 3 & $0.0 \%$ & 0 & $1.5 \%$ & 3 & \\
\hline Smoking status $(\%, N)$ & & & & & & & 0.055 \\
\hline Current smoker & $26.2 \%$ & 61 & $44.0 \%$ & 11 & $23.0 \%$ & 46 & \\
\hline Former smoker & $34.3 \%$ & 80 & $20.0 \%$ & 5 & $37.0 \%$ & 74 & \\
\hline Never smoker & $39.5 \%$ & 92 & $36.0 \%$ & 9 & $40.0 \%$ & 80 & \\
\hline Drinks alcohol $(\%, N)$ & $75.5 \%$ & 176 & $84.0 \%$ & 21 & $75.0 \%$ & 150 & 0.421 \\
\hline Exercise $(\%, N)$ & $51.1 \%$ & 119 & $56.0 \%$ & 14 & $49.0 \%$ & 98 & 0.509 \\
\hline Length of arthritis diagnosis, years ${ }^{\mathrm{a}}$ (Mean, SD) & 8.4 & 11.3 & 12.0 & 16.2 & 7.9 & 10.5 & 0.100 \\
\hline Number of joints affected (Mean, SD) & 2.0 & 1.9 & 1.8 & 2.2 & 1.9 & 1.7 & 0.712 \\
\hline \multicolumn{8}{|l|}{ Site affected by arthritis } \\
\hline Ankles & $15.9 \%$ & 37 & $20.0 \%$ & 5 & $14.5 \%$ & 29 & 0.551 \\
\hline Elbows & $13.3 \%$ & 31 & $12.0 \%$ & 3 & $13.5 \%$ & 27 & 1.000 \\
\hline Feet & $14.6 \%$ & 34 & $20.0 \%$ & 5 & $14.0 \%$ & 28 & 0.382 \\
\hline Fingers/Hands & $26.2 \%$ & 59 & $20.0 \%$ & 5 & $27.0 \%$ & 54 & 0.453 \\
\hline Hips & $14.2 \%$ & 33 & $24.0 \%$ & 6 & $12.5 \%$ & 25 & 0.126 \\
\hline Knees & $51.9 \%$ & 121 & $32.0 \%$ & 8 & $54.0 \%$ & 108 & 0.055 \\
\hline Neck & $10.3 \%$ & 24 & $8.0 \%$ & 2 & $10.5 \%$ & 21 & 1.000 \\
\hline Shoulders & $14.2 \%$ & 33 & $8.0 \%$ & 2 & $15.0 \%$ & 30 & 0.544 \\
\hline Spine & $3.0 \%$ & 7 & $4.0 \%$ & 1 & $2.5 \%$ & 5 & 0.511 \\
\hline Wrists & $16.7 \%$ & 39 & $20.0 \%$ & 5 & $16.5 \%$ & 33 & 0.584 \\
\hline Other & $6.0 \%$ & 14 & $8.0 \%$ & 2 & $5.5 \%$ & 11 & 0.643 \\
\hline Severity of arthritis $(\%, N)$ & & & & & & & 0.356 \\
\hline Mild & $51.5 \%$ & 120 & $56.0 \%$ & 14 & $52.0 \%$ & 104 & \\
\hline
\end{tabular}


Table 2 Sociodemographic and osteoarthritis characteristics by absenteeism among respondents with osteoarthritis in Japan, 2014 (Continued)

\begin{tabular}{|c|c|c|c|c|c|c|c|}
\hline \multirow[b]{3}{*}{ Moderate } & \multirow{2}{*}{\multicolumn{2}{|c|}{ Total $(N=233)$}} & \multicolumn{4}{|c|}{ Absenteeism $^{a}$} & \multirow{3}{*}{$p$-value } \\
\hline & & & \multicolumn{2}{|c|}{ Absenteeism $(N=25)$} & \multicolumn{2}{|c|}{ No Absenteeism $(N=200)$} & \\
\hline & $38.6 \%$ & 90 & $28.0 \%$ & 7 & $39.0 \%$ & 78 & \\
\hline Severe & $9.9 \%$ & 23 & $16.0 \%$ & 4 & $9.0 \%$ & 18 & \\
\hline Frequency of problems with arthritis $(\%, \mathrm{~N})$ & & & & & & & 0.032 \\
\hline Daily & $33.0 \%$ & 77 & $24.0 \%$ & 6 & $33.0 \%$ & 66 & \\
\hline 4-6 times a week & $7.7 \%$ & 18 & $16.0 \%$ & 4 & $6.5 \%$ & 13 & \\
\hline 2-3 times a week & $12.9 \%$ & 30 & $32.0 \%$ & 8 & $11.0 \%$ & 22 & \\
\hline Once a week & $2.6 \%$ & 6 & $0.0 \%$ & 0 & $3.0 \%$ & 6 & \\
\hline $2-3$ times a month & $14.2 \%$ & 33 & $12.0 \%$ & 3 & $15.0 \%$ & 30 & \\
\hline Once a month or less often & $29.6 \%$ & 69 & $16.0 \%$ & 4 & $31.5 \%$ & 63 & \\
\hline Use a prescription for OA $(\%, N)$ & $32.6 \%$ & 76 & $44.0 \%$ & 11 & $31.0 \%$ & 62 & 0.015 \\
\hline
\end{tabular}

Note: $B M I$ body mass index, $C C l$ Charlson Comorbidity Index, $O A$ osteoarthritis

*Differences between none vs. any absenteeism were performed using t-tests for continuous variables and chi-square or Fisher exact (cells $<5$ ) tests for categorical variables

${ }^{\mathrm{a}}$ Data for absenteeism were missing for eight respondents. Data for length of diagnosis were missing for an additional 12 respondents overall

proportion of OA patients, and their HRQoL burden is relatively high.

Overall, findings indicated that presenteeism is much more common than absenteeism among employed adults with OA in Japan. It is possible this may be due to those patients with less severe pain opting to remain at work, rather than to take time off to manage their OA pain. Nevertheless, this situation is problematic, as their productivity may be considerably reduced while on the job. Taken together, physicians should be sensitive to those patients with less severe OA who remain at work, but may suffer from increased presenteeism and reduced HRQoL. To this end, results suggest that presenteeism may serve as a useful indicator for physicians to identify those workers with OA who may require additional pain management.

The current study also revealed significant differences in current use of prescription medication for OA, with the presenteeism group using prescription medications (to alleviate OA symptoms) at a significantly higher rate than the non-presenteeism group. This result is consistent with other research that reported an association between work impairment and OA severity [35] and between daily functioning and pain levels among patients with OA [36]. Higher use of prescription drugs among the presenteeism group could be related to the

Table 3 Health-related quality of life and depression by presenteeism among respondents with osteoarthritis in Japan, 2014

\begin{tabular}{|c|c|c|c|c|c|c|c|c|}
\hline & \multicolumn{2}{|c|}{ Total $(N=233)$} & \multicolumn{2}{|c|}{ Presenteeism $(N=166)$} & \multicolumn{2}{|c|}{ No presenteeism $(N=67)$} & \multirow[b]{2}{*}{$p$-value } & \multirow[b]{2}{*}{ Cohen's d } \\
\hline & Mean & SD & Mean & SD & Mean & SD & & \\
\hline MCS & 46.2 & 10.6 & 44.4 & 11.2 & 50.8 & 7.4 & $<0.001$ & 0.67 \\
\hline PCS & 47.5 & 7.5 & 46.1 & 7.8 & 50.9 & 5.5 & $<0.001$ & 0.71 \\
\hline Physical functioning & 44.3 & 15.5 & 42.0 & 16.7 & 50.1 & 10.2 & $<0.001$ & 0.59 \\
\hline Physical role limitations & 43.9 & 13.4 & 41.3 & 13.9 & 50.3 & 9.6 & $<0.001$ & 0.75 \\
\hline Bodily pain & 42.1 & 10.1 & 40.2 & 9.7 & 46.7 & 9.6 & $<0.001$ & 0.67 \\
\hline General health & 42.5 & 10.5 & 40.6 & 10.3 & 47.0 & 9.5 & $<0.001$ & 0.65 \\
\hline Vitality & 44.2 & 10.9 & 42.4 & 10.8 & 48.6 & 10.0 & $<0.001$ & 0.46 \\
\hline Social functioning & 44.8 & 12.9 & 42.5 & 13.4 & 50.7 & 9.3 & $<0.001$ & 0.71 \\
\hline Emotional role limitations & 45.9 & 12.6 & 44.2 & 13.2 & 50.3 & 9.4 & $<0.001$ & 0.53 \\
\hline Mental health & 46.2 & 11.4 & 44.1 & 11.6 & 51.3 & 8.8 & $<0.001$ & 0.70 \\
\hline SF-6D (health utility) & 0.69 & 0.12 & 0.67 & 0.12 & 0.74 & 0.10 & $<0.001$ & 0.63 \\
\hline PHQ-9 total score (depression) & 5.0 & 5.7 & 5.8 & 6.0 & 2.9 & 4.3 & $<0.001$ & 0.56 \\
\hline
\end{tabular}

Cohen's d reflects the difference between the means divided by the standard deviations for those with and without presenteeism. A difference of 0.2 is considered small, 0.5 is medium, and 0.8 is large. As Cohen's d value increases, the lower percentage of overlapping values are observed between groups 


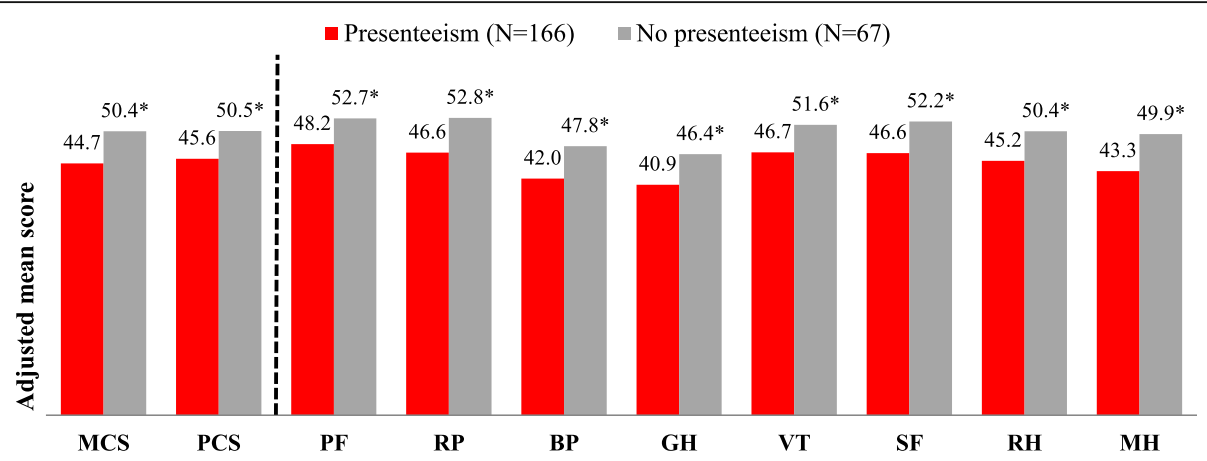

Fig. 1 Adjusted means of health-related quality of life metrics for OA patients with and without presenteeism ${ }^{\text {a }}$. Note: MCS = Mental Component Summary; $\mathrm{PCS}=$ Physical Component Summary; $\mathrm{PF}=$ physical functioning; $\mathrm{RP}=$ physical role limitation; $\mathrm{BP}=$ body pain; $\mathrm{GH}=$ general health; $\mathrm{VT}=$ vitality; $\mathrm{SF}=$ social functioning; $\mathrm{RH}$ = emotional role functioning; $\mathrm{MH}=$ mental health. Generalized linear models using a normal distribution were adjusted for age, education, and marital status (married or living with a partner vs. other). "Means were adjusted for age, education, and marital status. *Comparisons between groups were significant at $p \leq 0.001$

greater pain intensity experienced by that group. Kingsbury et al. indicated that the use of prescription medication rises when the severity of pain increases [12].

Furthermore, our study indicates that the relationship between presenteeism and HRQoL may extend beyond the workplace. In addition to greater use of OA medications, the presenteeism group also had greater impairment to both physical and mental HRQoL, as well as higher depression scores, compared with the no presenteeism group. Taken as a whole, these data are consistent with models relating pain severity to behavioral, cognitive, and emotional sequelae and to pain management interventions that use these models [37]. To illustrate, individuals with higher levels of pain may experience difficulty sleeping, thereby decreasing concentration and increasing presenteeism at work. This result is also in line with research in Japan that detected an association between presenteeism and depression [25].

\section{Limitations}

The data were collected using self-report and thus could be affected by recall bias. Inclusion criteria were based on patients' self-reported physician diagnosis and employment status in order to minimize selection bias and reflect the 'healthier' OA patient; those who indicated ever experiencing OA, but without a self-reported diagnosis were not included in this study. While the study design likely represents healthier patients who are able to fill out a survey, the low percentage of patients with absenteeism is representative of OA in Japan and of the Japanese population $[8,12,15]$. The cross-sectional design of this study did not allow for causality to be assessed. Since the data were also collected using an internet-based survey, the sample may also not be fully representative of the population of interest. Moreover, as with any group of instruments that measure the same construct, variations are shown across measures of presenteeism [38]. It is thus a possibility that slightly different results may be shown if another presenteeism instrument were used [38]. The nature of a selfreported study may also under- or overestimate the severity of the disease, however it has been shown that for OA, patient-reported severity is an acceptable measure of perceived health and should be used by providers during care management [39]. As this was a retrospective study, analyses could only adjust for those confounding variables collected in the survey. Finally, sites of OA were collected. However, since respondents could report multiple OA-affected sites, and the overall sample was relatively small, we were unable to draw conclusions based on an individual site of arthritis pain.

Table 4 Work and activity impairment by presenteeism among respondents with osteoarthritis in Japan, 2014

\begin{tabular}{lllll}
\hline & Total $(N=233)$ & Presenteeism $(N=166)$ & No presenteeism $(N=67)$ & $p$-value \\
\hline Absenteeism $\left.^{\text {a }}(\mathrm{N}) \mathrm{N}\right),(\mathrm{n}, \%)$ & $25(11.1 \%)$ & $24(15.1 \%)$ & $1(1.5 \%)$ & 0.002 \\
Absenteeism $^{\mathrm{a}}(\%),($ mean $\pm \mathrm{SD})$ & $2.1 \pm 9.2$ & $2.9 \pm 10.8$ & $0.0 \pm 0.4$ & 0.034 \\
Presenteeism (any), $(\mathrm{n}, \%)$ & $166(71.2 \%)$ & $166(100 \%)$ & $0(0 \%)$ & $\mathrm{NA}$ \\
Presenteeism (\%), (mean $\pm \mathrm{SD})$ & $27.0 \pm 26.7$ & $38.0 \pm 24.3$ & $0.0 \pm 0.0$ & $\mathrm{NA}$ \\
Overall work impairment (\%), (mean $\pm \mathrm{SD})$ & $27.9 \pm 27.7$ & $39.5 \pm 25.1$ & $0.0 \pm 0.4$ & $<0.001$ \\
Activity impairment $(\%),($ mean $\pm \mathrm{SD})$ & $29.5 \pm 27.6$ & $38.7 \pm 25.3$ & $6.7 \pm 18.5$ & $<0.001$ \\
\hline
\end{tabular}

${ }^{\mathrm{a}}$ There were eight respondents with missing data 
Table 5 Correlations between presenteeism and health-related quality of life among respondents with osteoarthritis in Japan, 2014

\begin{tabular}{lll}
\hline & Correlation $\left(r_{s}\right)$ & $p$-value \\
\hline MCS & -0.44 & $<0.001$ \\
PCS & -0.46 & $<0.001$ \\
SF-6D (health utility) & -0.51 & $<0.001$ \\
Physical functioning & -0.38 & $<0.001$ \\
Physical role limitations & -0.49 & $<0.001$ \\
Bodily pain & -0.44 & $<0.001$ \\
General health & -0.47 & $<0.001$ \\
Vitality & -0.43 & $<0.001$ \\
Social functioning & -0.48 & $<0.001$ \\
Emotional role limitations & -0.37 & $<0.001$ \\
Mental health & -0.45 & $<0.001$ \\
PHQ-9 total score (depression) & 0.42 & $<0.001$ \\
\hline
\end{tabular}

Note: MCS Mental Component Summary, PCS Physical Component Summary, PHQ-9 Patient Health Questionnaire-9, SF-6D Short-Form Six-Dimension

\section{Conclusions}

In this study, seven of every 10 OA patients experienced presenteeism, while only one out of 10 reported absenteeism. Presenteeism was greater among younger patients and those not married and not living with a partner. OA patients with than without presenteeism showed greater medication use, lower HRQoL across both mental and physical components, and higher depression scores. These findings demonstrate a need for workplace interventions and effective treatment options for workers in Japan who are diagnosed with OA.

\section{Abbreviations}

BMI: Body mass index; CCl: Charlson Comorbidity Index; MCS: Mental Component Summary; NHWS: National Health and Wellness Survey; OA: Osteoarthritis; PCS: Physical Component Summary; PHQ-9: Patient Health Questionnaire-9; SF-36v2: Revised Medical Outcomes Study 36-Item Short Form Health Survey; SF-6D: Short-Form Six-Dimensions; SPSS: Statistical Package for the Social Sciences; WPAI: Work Productivity and Activity Impairment Questionnaire

\section{Acknowledgements}

The authors acknowledge the editing assistance of Martine C. Maculaitis, $\mathrm{PhD}$, on behalf of Kantar Health, with funding from Shionogi \& Co., Ltd.

\section{Funding}

This study was funded by Shionogi \& Co., Ltd.

\section{Availability of data and materials}

Anonymized data used and/or analysed during the current study are available from the corresponding author on reasonable request.

\section{Authors' contributions}

All of the authors ( $K N, T$, JV and DJ) contributed to the conception of the study, drafting and critical revision of the manuscript, and provided final approval of the manuscript.

\section{Ethics approval and consent to participate}

The 2014 Japan NHWS was reviewed for exemption determination by Pear IRB (Indianapolis, IN, USA; study number 14-KAN-106) prior to participant recruitment and found to meet the exemption requirements under DHHS 45CFR46.101 regulations. All respondents viewed an on-line informed consent form and indicated their consent to participate prior to responding to the survey.

\section{Competing interests}

$\mathrm{KN}$ is no conflict of interest about this study. TT is full-time employees and stockholders of Shionogi \& Co., Ltd.. JV was and DJ is employed by Kantar Health, which received fees from Shionogi \& Co. Ltd., for access to Kantar Health's NHWS data, analysis, and reporting for this study.

\section{Publisher's Note}

Springer Nature remains neutral with regard to jurisdictional claims in published maps and institutional affiliations.

\section{Author details}

${ }^{1}$ Medicine for Sports and Performing Arts, Osaka University Graduate School of Medicine, Suita, Japan. ${ }^{2}$ Medical Affairs Department, Shionogi \& Co., Ltd., Osaka, Japan. ${ }^{3}$ Health Outcomes Practice, Kantar Health, Horsham, PA, USA. ${ }^{4}$ Health Outcomes Practice, Kantar Health, Ariel Sharon Street 4, 5230048 Tel Aviv, Israel.

Received: 9 May 2017 Accepted: 9 April 2018

Published online: 17 April 2018

\section{References}

1. Litwic A, Edwards MH, Dennison EM, Cooper C. Epidemiology and burden of osteoarthritis. Br Med Bull. 2013:105:185-99.

2. Zhang Y, Jordan JM. Epidemiology of osteoarthritis. Clin Geriatr Med. 2010; 26:355-69.

3. Xie F, Kovic B, Jin X, He X, Wang M, Silvestre C. Economic and humanistic burden of osteoarthritis: a systematic review of large sample studies. PharmacoEconomics. 2016:3:1087-100.

4. Hermans J, Koopmanschap MA, Bierma-Zeinstra SMA, Van Linge JH, Verhaar JAN, Reijman $\mathrm{M}$, et al. Productivity costs and medical costs among working patients with knee osteoarthritis. Arthritis Care Res. 2012;64:853-61.

5. Horikawa K, Kasai Y, Yamakawa T, Sudo A, Uchida A. Prevalence of osteoarthritis, osteoporotic vertebral fractures, and spondylolisthesis among the elderly in a Japanese village. J Orthop Surg (Hong Kong). 2006;14:9-12.

6. Nishimura A, Hasegawa M, Wakabayashi H, Yoshida K, Uchida A, Sudo A. Prevalence and characteristics of unilateral knee osteoarthritis in a community sample of elderly Japanese: do fractures around the knee affect the pathogenesis of unilateral knee osteoarthritis? J Orthop Sci. 2012;17:556-61.

7. Yoshimura N, Muraki S, Oka H, Mabuchi A, En-Yo Y, Yoshida M, et al. Prevalence of knee osteoarthritis, lumbar spondylosis, and osteoporosis in Japanese men and women: the research on osteoarthritis/osteoporosis against disability study. J Bone Miner Metab. 2009;27:620-8.

8. DaCosta Dibonaventura M, Gupta S, Mcdonald M, Sadosky A. Evaluating the health and economic impact of osteoarthritis pain in the workforce: results from the National Health and Wellness Survey. BMC Musculoskelet Disord. 2011;12:83.

9. Xie F. The need for standardization: a literature review of indirect costs of rheumatoid arthritis and osteoarthritis. Arthritis Care Res. 2008:59:1027-33.

10. Burton WN, Chen C-Y, Conti DJ, Schultz AB, Pransky G, Edington DWP. The association of health risks with on-the-job productivity. J Occup Environ Med. 2005;47:769-77.

11. Schultz AB, Chen C, Edington DW. The cost and impact of health conditions on presenteeism to employers: a review of the literature. Pharmaceconomics. 2009:27:365-78.

12. Kingsbury SR, Gross HJ, Isherwood G, Conaghan PG. Osteoarthritis in europe: impact on health status, work productivity and use of pharmacotherapies in five European countries. Rheumatology (United Kingdom). 2014;53:937-47.

13. Stewart WF, Ricci JA, Chee E, Morganstein D, Lipton R. Lost productive time and cost due to common pain conditions in the US workforce. JAMA. 2003; 29029018:2443-54.

14. Gignac MAM, Cao X, Lacaille D, Anis AH, Badley EM. Arthritis-related work transitions: a prospective analysis of reported productivity losses, work changes, and leaving the labor force. Arthritis Care Res. 2008;59:1805-13.

15. DiBonaventura M, Gupta S, McDonald M, Sadosky A, Pettitt D, Silverman S. Impact of self-rated osteoarthritis severity in an employed population: cross- 
sectional analysis of data from the national health and wellness survey. Health Qual Life Outcomes. 2012;10:30.

16. Harris EC, Coggon D. Hip osteoarthritis and work. Best Pract Res Clin Rheumatol. 2015:29:462-82.

17. Matsudaira K, Palmer KT, Reading I, Hirai M, Yoshimura N, Coggon D. Prevalence and correlates of regional pain and associated disability in Japanese workers. Occup Environ Med. 2011;68:191-6.

18. Takegami M, Yamzaki S, Greenhill A, Chang H, Fukuhara S. Work performance assessed by a newly developed version of the Work Limitation Questionnaire in a general Japanese adult population. J Occup Health. 2014 56:124-33.

19. Montgomery W, Vietri J, Shi J, Ogawa K, Kariyasu S, Alev L, et al. The relationship between pain severity and patient-reported outcomes among patients with chronic low back pain in Japan. J Pain Res. 2016;9:337-44.

20. Muraki S, Akune T, Oka H, En-yo Y, Yoshida M, Saika A, et al. Association of radiographic and symptomatic knee osteoarthritis with health-related quality of life in a population-based cohort study in Japan: the ROAD study. Osteoarthr Cartil. 2010;18:1227-34.

21. Agaliotis M, Mackey MG, Jan S, Fransen M. Burden of reduced work productivity among people with chronic knee pain: a systematic review. Occup Environ Med. 2014;71:651-9.

22. Matsudaira K, Konishi H, Miyoshi K, Isomura T, Inuzuka K. Potential risk factors of persistent low back pain developing from mild low back pain in urban Japanese workers. PLoS One. 2014;9:5-10.

23. Sadosky AB, DiBonaventura M, Cappelleri JC, Ebata N, Fujii K. The association between lower back pain and health status, work productivity, and health care resource use in Japan. J Pain Res. 2015;8:119-30.

24. Okumura Y, Higuchi T. Cost of depression among adults in Japan cost-ofillness methodology. Prim Care Companion CNS Disord. 2011;13(3).

25. Wada K, Arakida M, Watanabe R, Negishi M, Sato J, Tsutsumi A. The economic impact of loss of performance due to absenteeism and presenteeism caused by depressive symptoms and comorbid health conditions among Japanese workers. Ind Health. 2013;51:482-9.

26. Tachi T, Teramachi H, Tanaka K, Asano S, Osawa T, Kawashima A, et al. The impact of side effects from outpatient chemotherapy on presenteeism in breast cancer patients: a prospective analysis. Spring. 2016;5:327.

27. Yamada M, Mizuno Y, Shigeyasu C. Impact of dry eye on work productivity. Clin Outcomes Res. 2012;4:307-12.

28. Reilly MC, Zbrozek AS, Dukes EM. The validity and reproducibility of a work productivity and activity impairment instrument. PharmacoEconomics. 1993;4:353-65.

29. Maruish ME, editor. NEW SF36v2 User Guide. 3rd ed; 2011.

30. Brazier J, Roberts J, Deverill M. The estimation of a preference-based measure of health from the SF-36. J Health Econ. 2002:21:271-92.

31. Fukuhara S, Suzukamo Y. Manual of SF-36v2 Japanese version. Kyoto Inst Heal Outcomes Process Eval Res. 2004:b20.

32. Kroenke K, Spitzer RL, Williams JBW. The PHQ-9: validity of a brief depression severity measure. J Gen Intern Med. 2001;16:606-13.

33. Charlson ME, Pompei P, Ales KL, MacKenzie CR. A new method of classifying prognostic comorbidity in longitudinal studies: development and validation. J Chronic Dis. 1987:40:373-83.

34. Cohen J. Statistical power analysis for the behavioral sciences. Oxford: Routledge; 1988.

35. Sadosky AB, Taylor-Stokes G, Lobosco S, Pike J, Ross E. Relationship between self-reported low-back pain severity and other patient-reported outcomes: results from an observational study. J Spinal Disord Tech. 2013;26:8-14.

36. Hutchings A, Calloway M, Choy E, Hooper M, Hunter DJ, Jordan JM, et al. The longitudinal examination of arthritis pain (LEAP) study: relationships between weekly fluctuations in patient-rated joint pain and other health outcomes. J Rheumatol. 2007;34:2291-300.

37. Vitiello MV, McCurry SM, Shortreed SM, Baker LD, Rybarczyk BD, Keefe FJ, et al. Short-term improvement in insomnia symptoms predicts long-term improvements in sleep, pain, and fatigue in older adults with comorbid osteoarthritis and insomnia. Pain. 2014;155:1547-54.

38. Zhang W, Gignac MAM, Beaton D, Tang K, Anis AH. Productivity loss due to presenteeism among patients with arthritis: estimates from 4 instruments. J Rheumatol. 2010;37:1805-14.

39. Sadosky AB, Bushmakin AG, Cappelleri JC, Lionberger DR. Relationship between patient-reported disease severity in osteoarthritis and self-reported pain, function and work productivity. Arthritis Res Ther. 2010;12:R162.

\section{Ready to submit your research? Choose BMC and benefit from:}

- fast, convenient online submission

- thorough peer review by experienced researchers in your field

- rapid publication on acceptance

- support for research data, including large and complex data types

- gold Open Access which fosters wider collaboration and increased citations

- maximum visibility for your research: over $100 \mathrm{M}$ website views per year

At BMC, research is always in progress.

Learn more biomedcentral.com/submissions 